\title{
Ground motions for FEMA P-695 application in subduction zones
}

\author{
Xavier Estrella ${ }^{a, b *}$ (i) \\ Pablo Guindos ${ }^{b, c}$ \\ José Luis Almazán \\ a University of Technology Sydney, 81 Broadway Street, Ultimo NSW 2007, Australia. E-mail: xavestrella@gmail.com \\ b Pontificia Universidad Católica de Chile, Av. Vicuña Mackenna, Santiago 7820436, Chile. E-mail: pguindos@ing.puc.cl, jlalmaza@ing.puc.cl \\ c UC Timber Innovation Center, Av. Vicuña Mackenna, Santiago 7820436, Chile \\ * Corresponding author
}

https://doi.org/10.1590/1679-78255848

\begin{abstract}
The FEMA P-695 report presents a methodology for the rational quantification of seismic performance factors for use in seismic design. Despite the fact that the methodology is comprehensive and covers a wide range of possible applications, it only provides ground motion sets recorded from shallow crustal earthquakes. Therefore, this paper presents a new set of ground motions aimed at extending the scope of the FEMA P-695 methodology to zones prone to subduction earthquakes. To consider the effect of spectral shapes on collapse capacities, the spectral shape factors SSF were also computed. Four light-frame buildings were analyzed to study the impact of using the new ground motion set. Results showed a decrease in collapse capacities of $12.4 \%$, an increase in peak floor accelerations of $31.7 \%$, and an increase in the dissipated hysteretic energy of $15.7 \%$. Additionally, the number of ground motions and the intensity levels of the set proved to be robust enough to provide the same reliability that can be obtained when employing a much larger ground motion set. The ground motions and the information provided in this paper have been designed to be fully consistent with the FEMA P-695 guidelines. However, their application can be extended to other analyses that evaluate the seismic performance of structural systems in subduction areas. A database that includes the proposed ground motion set is available online.
\end{abstract}

\section{Keywords}

Ground motion selection, incremental dynamic analysis, FEMA P-695 subduction zones.

\section{INTRODUCTION}

Ground motion selection plays a fundamental role when evaluating the seismic performance of structural systems through dynamic analyses, because at the same time that the records have to reflect both the seismic hazard and the shallow geology of the area under study, they also have to consider the randomness and uncertainty inherent in the seismic demand (lervolino et al., 2008). Generally speaking, there are three different ways to obtain seismic records: (1) artificially generated waveforms (spectrum-compatible accelerograms); (2) simulated accelerograms from seismological models; and (3) natural records. Although these three approaches have been widely used in seismic engineering, previous research has shown that natural accelerograms are more suitable than spectrum-compatible ones and more readily available than synthetic records derived from seismological fault models (Bommer and Acevedo, 2004).

The methodology for the rational quantification of seismic design factors proposed by the Federal Emergency Management Agency (FEMA) employs incremental dynamic analyses (IDA) as a tool to evaluate the performance and collapse capacity of structural systems. An IDA analysis (Vamvatsikos and Cornell, 2002) consists of multiple responsehistory analyses for a ground motion with increasing intensity until the structure reaches collapse or a given limit state. 
Due to the variability in the seismic demand, this process has to be repeated for a set with a statistically significant number of ground motions such that it allows determining the average intensity that causes collapse as well as evaluating the variability of the set employed. Given this context, the FEMA P-695 (FEMA, 2009) methodology provides two sets of ground motions to be used in the analyses, the first with 22 pairs of far-field accelerograms recorded at sites located more than $10 \mathrm{~km}$ from the fault rupture, and the second with 28 pairs of near-field ground motions recorded at sites located less than $10 \mathrm{~km}$ from the fault rupture, which is subdivided into 14 impulsive and 14 non-impulsive records. The accelerograms were extracted from the PEER NGA database (PEER, 2002), and a detailed description of their selection can be found in the report published by FEMA (2009).

Both the far-field and near-field sets consist of records from shallow crustal earthquakes, which are representative of areas in the Western United States. Therefore, they do not include strong motion records from Central and Eastern United States earthquakes, or from deep subduction earthquakes such as those expected in Japan, New Zealand, or in areas on the Pacific Coast in South America. Subduction earthquakes are known to have longer durations than shallow crustal ones, to release more energy, and to induce more damage even to buildings designed with modern codes. Duration of seismic records is a key factor when evaluating the collapse capacity of structural systems prone to degradation (Chandramohan, 2016; Foschaar et al., 2012; Raghunandan and Liel, 2013). Furthermore, ground motions related to deep subduction earthquakes are also known to have, on average, stronger accelerations of greater length. For instance, a study conducted by Chandramohan et al. (2016) showed that the estimated median collapse capacity is $29 \%$ lower when using a long-duration ground motion set compared to a short-duration set. Raghunandan et al. (2015) also found that the median collapse capacity of ductile buildings designed with modern codes is $40 \%$ lower when subjected to subduction ground motions compared to crustal earthquakes. Interestingly, the researchers found that although the duration of the records has no impact on the peak structural response, long-duration ground motions impose higher energy demands which are more damaging for structural systems.

A careful selection of the set to employ allows for achieving the same reduction of bias and variation in the structural response that would be obtained by using more complex indicators of the records intensity, while still allowing the use of simple tools for processing the ground motions, such as elastic response spectra (Baker and Cornell, 2005; Shome and Cornell, 1999). For this reason, several methodologies have been proposed in the literature to select accelerograms for non-linear analyses, which are based on different selection criteria such as magnitude, distance to fault, soil profile, strong motion duration, seismotectonic environment, acceleration-to-velocity ratio, among others (Katsanos et al., 2010). More complex methodologies have also been developed, such as record selection based on spectral matching (Bommer et al., 2003), ground motion intensity measures (Cornell, 2005), the spectral shape (Baker and Cornell, 2006), or the conditional mean spectrum (Baker, 2010). The objective behind all these approaches is to choose ground motions that represent as accurately as possible the seismic demand that buildings will be subjected to during an earthquake at a given zone. Regarding the application of the FEMA P-695 methodology, there are previous investigations in the current literature have extended its scope to areas prone to earthquakes other than shallow crustal ones. For instance, AlHamaydeh et al. (2011), Bezabeh et al. (2016), Vielma and Cando (2017), and Ccanchi and Taboada (2018) developed sets of ground motions to apply the FEMA P-695 methodology in zones prone to subduction earthquakes. However, such sets are not suitable to be used in research projects other than the ones for which the ground motion sets were developed for, because either they are not consistent with guidelines of the methodology, are site-specific, or do not take into account the effects of the spectral shapes.

The lack of a well-established set of subduction ground motions restricts an extended and proper application of the methodology. Therefore, this paper proposes a set of ground motions for the application of the FEMA P-695 methodology in subduction zones, as well as the normalization factors for each accelerogram and the spectral shape factors (SSF) to adjust the collapse margin ratios obtained from incremental dynamic analyses.

\section{GROUND MOTION SELECTION}

A set of criteria was established before the selection of the ground motions, which are consistent with those proposed in the FEMA methodology (2009) and are intended to provide an objective selection of the records. Each criterion is listed below, followed by a brief description of it.

- Earthquake magnitude. A minimum magnitude of $M \geq 6.5$ was established as a requirement. This is because largemagnitude earthquakes have strong ground motions of greater duration which release more energy. As a result, higher risks of structural collapse are expected. Earthquakes of lesser magnitude $(M<6.5)$ can cause significant damage to structural and non-structural elements. However, they are unlikely to cause collapse of structural systems designed with modern requirements (FEMA, 2009). 
- Fault type. Due to the complex characteristics of the shallow Earth's crust, most subduction areas are also threatened by potentially dangerous shallow crustal earthquakes. For instance, the city of Santiago (Chile) is exposed to both the ongoing subduction of the Nazca Plate under the South American Plate, and the San Ramón fault (a thrust fault across the city). Therefore, to adequately embrace the different seismic scenarios, ground motions from shallow crustal earthquakes (strike-slip and thrust) and deep subduction earthquakes have been selected for this set, noting that there are few available records of the latter for engineering use.

- Distance to the fault. A minimum distance of $10 \mathrm{~km}$ has been considered, which is consistent with the concept of far-field zone proposed in the design maps for the maximum considered earthquake by the ASCE/SEI 7-16 standard (ASCE, 2016).

- Components. Records with two horizontal orthogonal components were selected. The existence of a vertical component was not considered as a selection criterion.

- Intensity measures. Limits of peak ground acceleration (PGA) $>0.2 \mathrm{~g}$ and peak ground velocity $(P G V)>15 \mathrm{~cm} / \mathrm{s}$ were set for each of the orthogonal components. Although these values are arbitrary, it is considered that they represent the structural damage limit for buildings designed using modern seismic codes (FEMA, 2009).

- Number of records per earthquake. To avoid bias towards more recent events that have been better and more widely recorded, a limit of two records per earthquake was set in case there were several ones matching with the selection criteria.

- Accelerogram correction. Only ground motions with instrumental and baseline correction were included in the set.

- Soil conditions. Ground motions recorded on soft rock (Site Class C) or stiff soil (Site Class D) sites were included.

Based on the aforementioned criteria, a set of 26 pairs of ground motions (horizontal components) was developed, which were obtained from reports published by seismological agencies of different countries. The robustness of this number of ground motions is validated later in this paper. To avoid bias towards a particular seismic region, records were chosen regardless of the country of origin. Table 1 shows a summary of the proposed set as well as additional information of the ground motions.

The normalization and scaling process of the records for use in incremental dynamic analyses are standardized for the application of the FEMA P-695 methodology. The details of these processes are described subsequently. Table 2 shows information about PGA, PGV, 1-second spectral acceleration, significant duration $\mathrm{Ds}_{5-75}$, lowest usable frequency, and fault type of the selected ground motions.

Table 1 General information about the ground motions selected for the set.

\begin{tabular}{|c|c|c|c|c|c|c|}
\hline \multirow{2}{*}{$\#$} & \multicolumn{4}{|c|}{ Earthquake } & \multicolumn{2}{|c|}{ Recording station } \\
\hline & Name & Magnitude & Year & Country & Name & Source \\
\hline 1 & Arequipa & 8.4 & 2001 & Peru & Arica Costanera & Renadic \\
\hline 2 & Arequipa & 8.4 & 2001 & Peru & Poconchile & Renadic \\
\hline 3 & Cape Mendocino & 7.0 & 1992 & USA & Rio Dell Overpass & CDMG \\
\hline 4 & Coquimbo & 8.4 & 2015 & Chile & C110 & CSN \\
\hline 5 & Coquimbo & 8.4 & 2015 & Chile & $\mathrm{C} 260$ & CSN \\
\hline 6 & Chi-Chi & 7.6 & 1999 & Taiwan & TCU045 & CWB \\
\hline 7 & Duzce & 7.1 & 1999 & Turkey & Bolu & ERD \\
\hline 8 & Iquique & 8.2 & 2014 & Chile & T03A & CSN \\
\hline 9 & Iquique & 8.2 & 2014 & Chile & T10A & CSN \\
\hline 10 & Kaikoura & 7.8 & 2016 & New Zealand & CULC20 & EQC \\
\hline 11 & Kobe & 6.9 & 1995 & Japan & Nishi-Akashi & CUE \\
\hline 12 & Landers & 7.3 & 1992 & USA & Coolwater & SCE \\
\hline 13 & Las Colinas & 7.7 & 2001 & El Salvador & EX01001U & UCA \\
\hline 14 & Loma Prieta & 6.9 & 1989 & USA & Capitola & CDMG \\
\hline 15 & Maule & 8.8 & 2010 & Chile & Angol & Renadic \\
\hline 16 & Maule & 8.8 & 2010 & Chile & StgoCentro & Renadic \\
\hline 17 & Mejillones & 6.7 & 2007 & Chile & Mejillones Puerto & Renadic \\
\hline 18 & Northridge & 6.7 & 1994 & USA & Canyon Country & USC \\
\hline
\end{tabular}


Table 1 Continued..

\begin{tabular}{|c|c|c|c|c|c|c|}
\hline \multirow{2}{*}{$\#$} & \multicolumn{4}{|c|}{ Earthquake } & \multicolumn{2}{|c|}{ Recording station } \\
\hline & Name & Magnitude & Year & Country & Name & Source \\
\hline 19 & Pedernales & 7.8 & 2016 & Ecuador & AMNT & RENAC \\
\hline 20 & Pedernales & 7.8 & 2016 & Ecuador & APO1 & RENAC \\
\hline 21 & Superstition Hills & 6.5 & 1987 & USA & El Centro Imp. Co. & CDMG \\
\hline 22 & Tarapaca & 7.9 & 2005 & Chile & Cuya & Renadic \\
\hline 23 & Tocopilla & 7.7 & 2007 & Chile & Papudo & Renadic \\
\hline 24 & Tocopilla & 7.7 & 2007 & Chile & Tocopilla & Renadic \\
\hline 25 & Tohoku & 9.0 & 2011 & Japan & IBR011 & NIED \\
\hline 26 & Tohoku & 9.0 & 2011 & Japan & IBR012 & NIED \\
\hline
\end{tabular}

The ground motions were selected such that $2 / 3$ were subduction records and $1 / 3$ crustal ones. Hence, the proposed set includes 18 records from subduction earthquakes and 8 from shallow crustal earthquakes, of which 3 are from thrust faults and 5 from strike-slip faults. A period of approximately 30 years has been covered, with information recorded from 1987 until the recent earthquake in Kaikoura (New Zealand) in 2016. Earthquake magnitudes range from $M=6.5$ for the Superstition Hills (USA) strike-slip earthquake, to $M=9.0$ for the Japanese earthquake of Tohoku in 2011. The average magnitude of the set is $M=7.8$.

Table 2 Information about PGA, PGV, 1-second spectral acceleration ( $\xi=5 \%$ ), significant duration Ds5-75, lowest usable frequency, and fault type.

\begin{tabular}{|c|c|c|c|c|c|c|c|c|c|c|}
\hline \multirow{2}{*}{$\#$} & \multicolumn{2}{|c|}{ PGA [g] } & \multicolumn{2}{|c|}{$\mathrm{PGV}[\mathrm{cm} / \mathrm{s}]$} & \multicolumn{2}{|c|}{$\mathrm{Sa}_{1 \mathrm{~s}}[\mathrm{~g}]$} & \multicolumn{2}{|c|}{$\mathrm{Ds}_{5-75}[\mathrm{~s}]$} & \multirow{2}{*}{$\begin{array}{c}\text { Lowest freq } \\
{[\mathrm{Hz}]}\end{array}$} & \multirow{2}{*}{ Fault type } \\
\hline & C1 & C2 & C1 & $\mathrm{C2}$ & C1 & C2 & C1 & C2 & & \\
\hline 1 & 0.34 & 0.27 & 25.22 & 24.65 & 0.38 & 0.33 & 9.20 & 10.42 & 0.15 & Subduction \\
\hline 2 & 0.25 & 0.26 & 29.57 & 29.10 & 0.33 & 0.27 & 9.77 & 9.62 & 0.15 & Subduction \\
\hline 3 & 0.39 & 0.55 & 43.81 & 41.88 & 0.54 & 0.39 & 4.25 & 1.92 & 0.07 & Thrust \\
\hline 4 & 0.83 & 0.71 & 36.60 & 42.83 & 0.29 & 0.17 & 17.02 & 20.79 & 0.01 & Subduction \\
\hline 5 & 0.36 & 0.23 & 34.21 & 24.62 & 0.56 & 0.23 & 21.90 & 28.50 & 0.01 & Subduction \\
\hline 6 & 0.51 & 0.47 & 39.07 & 36.70 & 0.43 & 0.30 & 8.74 & 7.43 & 0.05 & Thrust \\
\hline 7 & 0.73 & 0.82 & 56.44 & 62.10 & 0.72 & 1.16 & 2.62 & 1.47 & 0.06 & Strike-slip \\
\hline 8 & 0.58 & 0.61 & 35.10 & 18.82 & 0.27 & 0.14 & 25.11 & 27.76 & 0.01 & Subduction \\
\hline 9 & 0.66 & 0.78 & 37.55 & 47.99 & 0.52 & 0.45 & 22.50 & 21.11 & 0.01 & Subduction \\
\hline 10 & 0.22 & 0.25 & 22.95 & 33.06 & 0.22 & 0.30 & 21.89 & 20.80 & 0.20 & Subduction \\
\hline 11 & 0.51 & 0.50 & 37.29 & 36.62 & 0.31 & 0.29 & 3.97 & 4.48 & 0.13 & Strike-slip \\
\hline 12 & 0.28 & 0.42 & 25.65 & 42.35 & 0.20 & 0.36 & 5.93 & 3.80 & 0.13 & Strike-slip \\
\hline 13 & 0.30 & 0.28 & 25.81 & 17.88 & 0.45 & 0.40 & 9.59 & 11.07 & 0.20 & Subduction \\
\hline 14 & 0.53 & 0.44 & 35.01 & 29.22 & 0.46 & 0.28 & 5.74 & 5.55 & 0.13 & Strike-slip \\
\hline 15 & 0.70 & 0.93 & 37.65 & 34.31 & 0.46 & 0.21 & 30.23 & 23.03 & 0.15 & Subduction \\
\hline 16 & 0.21 & 0.31 & 21.92 & 25.65 & 0.27 & 0.22 & 23.05 & 20.31 & 0.15 & Subduction \\
\hline 17 & 0.39 & 0.47 & 32.33 & 17.97 & 0.19 & 0.09 & 5.41 & 4.47 & 0.15 & Subduction \\
\hline 18 & 0.41 & 0.48 & 42.97 & 44.91 & 0.38 & 0.63 & 3.15 & 2.94 & 0.13 & Thrust \\
\hline 19 & 0.52 & 0.40 & 43.10 & 55.27 & 0.44 & 0.39 & 5.79 & 7.38 & 0.20 & Subduction \\
\hline 20 & 0.38 & 0.32 & 47.57 & 42.55 & 0.30 & 0.30 & 5.73 & 5.62 & 0.20 & Subduction \\
\hline 21 & 0.36 & 0.26 & 46.36 & 40.87 & 0.31 & 0.25 & 7.01 & 7.59 & 0.13 & Strike-slip \\
\hline 22 & 0.44 & 0.45 & 18.51 & 18.42 & 0.08 & 0.10 & 12.46 & 15.67 & 0.15 & Subduction \\
\hline 23 & 0.30 & 0.42 & 16.15 & 24.63 & 0.08 & 0.09 & 20.16 & 19.00 & 0.15 & Subduction \\
\hline 24 & 0.50 & 0.59 & 20.89 & 21.53 & 0.14 & 0.18 & 12.45 & 11.62 & 0.15 & Subduction \\
\hline 25 & 0.34 & 0.35 & 25.31 & 41.76 & 0.29 & 0.58 & 41.66 & 36.10 & 0.20 & Subduction \\
\hline 26 & 0.29 & 0.30 & 40.59 & 30.94 & 0.71 & 0.37 & 48.30 & 45.17 & 0.20 & Subduction \\
\hline
\end{tabular}


Ground motion duration was characterized by means of the significant duration parameter Ds5-75, since it has been widely used in the literature and previous research has shown that it is a suitable metric when analyzing the effect of ground motion duration on the response of structural systems (Foschaar et al., 2012). The Ds5-75 parameter is defined as the time interval over which a particular percentage of the following integral is accumulated

$$
\int_{0}^{t_{\operatorname{trax}}}[a(t)]^{2} d t
$$

where $a(t)$ represents the ground acceleration, and $t_{\max }$ represents the length of the record. The average Ds $5-75$ for the ground motions set proposed in this paper is $14.56 \mathrm{~s}$, while for the FEMA P-695 far-field set is $6.54 \mathrm{~s}$. As can be noted, due to the intrinsic properties of the fault mechanism, the inclusion of subduction records increases the average significant duration of the set more than twice. As previous research has shown, this latter is expected to exert a statistically significant influence on structural collapse capacity (Chandramohan et al., 2016).

Figure 1(a) shows the response spectra for the 26 pairs of ground motions, as well as the average spectrum of the set plus one and two standard deviations. The average spectral acceleration for short periods is about $0.8 \mathrm{~g}$, and for $\mathrm{T}_{\mathrm{n}}=1 \mathrm{~s}$ it approaches to $0.35 \mathrm{~g}$. The transition from the constant acceleration domain to the constant velocity domain occurs approximately at $T_{n}=0.5 \mathrm{~s}$, a result consistent with the expected response of soft rock sites or rigid soils.

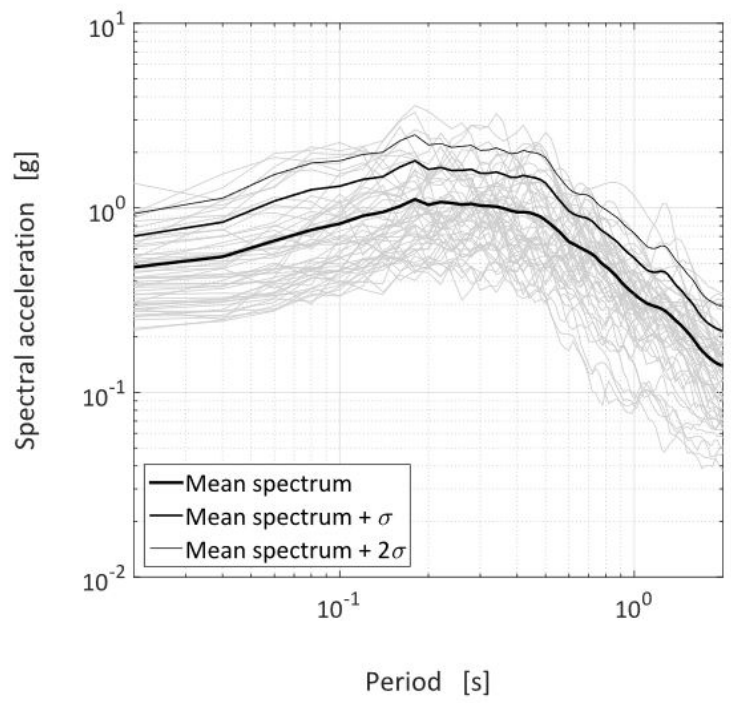

(a)

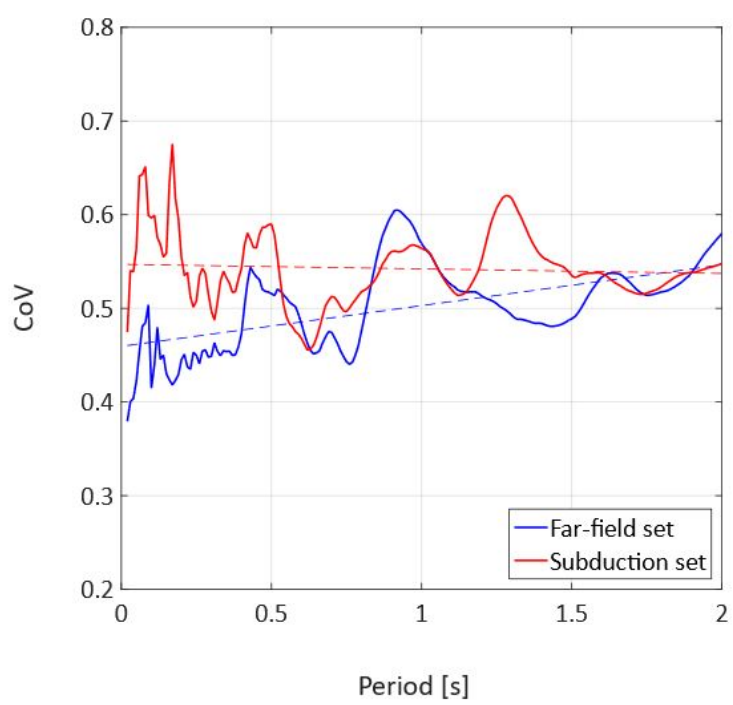

(b)

Figure 1 (a) Response spectra for the 26 pairs of ground motions and average spectrum of the set plus one and two standard deviations; (b) coefficient of variation as a function of $T$ for both subduction and far-field set.

The variability in the spectral acceleration of the proposed ground motion set was analyzed as a function of $T$ and compared with that of the FEMA P-695 far-field set. The proxy to measure the variability was the coefficient of variation $\mathrm{CoV}$, defined as the ratio between the standard deviation and the mean spectral acceleration for a given period T. Figure 1 (b) shows that the CoV values are similar for both ground motion sets. For the subduction set, it is about 0.55 for both short and long periods, whereas for the far-field set it ranges from 0.45 at short periods to 0.55 at long periods. These variability levels are consistent with the dispersion values of typical ground motion prediction equations GMPE (Campbell and Borzorgnia, 2003), and are due to the differences in site conditions, source, epicentral distance, and event magnitude.

\section{NORMALIZATION AND SCALING}

In order to determine the collapse capacity of structural archetypes through IDA analyses, it is necessary to follow a scaling protocol of the seismic records such that they increase their intensity progressively until a given limit state is reached. This is because there are almost no natural accelerograms that are capable of causing collapse of modern 
structures (FEMA, 2009). Before scaling the records, it is required to apply a normalization process, which is standard for the FEMA methodology P-695 and is detailed in the following paragraphs.

Normalization is a simple approach to eliminate the variability due to differences in the magnitude of the earthquake, type of fault, soil, and hypocentral distance, while still maintaining the intrinsic randomness of the records for an adequate probabilistic evaluation. Normalization is performed based on the geometric mean of the PGV of the two components, a parameter commonly used for the characterization of ground motions. In accordance with the FEMA P-695 methodology, the normalization factors are calculated as

$$
N F_{i}=\frac{\operatorname{median}\left(P G V_{s e t}\right)}{P G V_{i}}
$$

where $\mathrm{NF}_{i}$ is the factor to be applied to each component of the $i$ record, $\mathrm{PGV}_{i}$ is the geometric mean of the PGV values of the two components, and median $\left(\mathrm{PGV}_{\text {set }}\right)$ is the median of all the $\mathrm{PGV}_{i}$ values in the set. For the set in this paper, median $\left(\mathrm{PGV}_{\text {set }}\right)=32.73 \mathrm{~cm} / \mathrm{s}$. Depending on the $\mathrm{PGV}_{i}$ values, the record can be amplified if $\mathrm{NF}_{i}>1$ or reduced if $\mathrm{NF}_{i}<1$. Table 3 shows the $\mathrm{NF}_{i}$ factors as well as other properties of interest of the accelerograms after the normalization process.

Figure 2(a) shows the elastic response spectra of the 26 pairs of normalized ground motions, as well as the mean spectrum with one and two standard deviations. As observed, the average spectral acceleration for short periods is about $1.0 \mathrm{~g}$, and for $T_{n}=1 \mathrm{~s}$, it is about $0.30 \mathrm{~g}$. The transition from the constant acceleration domain to the constant velocity domain occurs about $T_{n}=0.35 \mathrm{~s}$. Interestingly, it has been found that a normalization process based on the geometric mean of the PGV is not very effective in reducing the variability of the ground motions set. Figure 2(b) shows the CoV for the subduction set before and after normalization. On average, there is a variability reduction of $13 \%$; however, for periods shorter than $0.3 \mathrm{~s}$ the normalization procedure slightly increased the variability in the set. Similar results were found for the FEMA P-695 far-field set. Nevertheless, the calculation of collapse capacities is not affected by this issue, since each ground motion is scaled separately until collapse when performing incremental dynamic analyses.

Table 3 Normalization factors $\mathrm{NF}_{i}$ for each ground motion, as well as PGA, PGV and 1-second spectral acceleration $(\xi=5 \%)$ of both horizontal components after normalization.

\begin{tabular}{|c|c|c|c|c|c|c|c|}
\hline \multirow{2}{*}{$\#$} & \multirow{2}{*}{$\begin{array}{l}\text { Normalization } \\
\text { factors }\end{array}$} & \multicolumn{2}{|c|}{ PGA [g] } & \multicolumn{2}{|c|}{ PGV $[\mathrm{cm} / \mathrm{s}]$} & \multicolumn{2}{|c|}{$\mathrm{Sa}_{1 \mathrm{~s}}[\mathrm{~g}]$} \\
\hline & & C1 & C2 & C1 & C2 & C1 & $\mathrm{C} 2$ \\
\hline 1 & 1.31 & 0.44 & 0.36 & 33.11 & 32.36 & 0.50 & 0.43 \\
\hline 2 & 1.12 & 0.27 & 0.29 & 32.99 & 32.48 & 0.36 & 0.30 \\
\hline 3 & 0.76 & 0.29 & 0.42 & 33.48 & 32.00 & 0.41 & 0.30 \\
\hline 4 & 0.89 & 0.74 & 0.64 & 36.16 & 29.64 & 0.26 & 0.15 \\
\hline 5 & 1.09 & 0.40 & 0.25 & 37.76 & 28.38 & 0.60 & 0.25 \\
\hline 6 & 0.86 & 0.44 & 0.41 & 33.78 & 31.72 & 0.37 & 0.26 \\
\hline 7 & 0.55 & 0.40 & 0.45 & 31.21 & 34.34 & 0.40 & 0.64 \\
\hline 8 & 1.30 & 0.75 & 0.79 & 41.14 & 26.04 & 0.36 & 0.18 \\
\hline 9 & 0.76 & 0.50 & 0.59 & 31.10 & 34.45 & 0.39 & 0.34 \\
\hline 10 & 1.19 & 0.26 & 0.30 & 27.27 & 39.29 & 0.26 & 0.36 \\
\hline 11 & 0.89 & 0.45 & 0.45 & 33.03 & 32.44 & 0.27 & 0.25 \\
\hline 12 & 0.99 & 0.28 & 0.41 & 25.47 & 42.06 & 0.20 & 0.36 \\
\hline 13 & 1.52 & 0.46 & 0.42 & 39.33 & 27.25 & 0.68 & 0.61 \\
\hline 14 & 1.02 & 0.54 & 0.45 & 35.83 & 29.90 & 0.47 & 0.28 \\
\hline 15 & 0.91 & 0.63 & 0.85 & 34.29 & 31.25 & 0.42 & 0.19 \\
\hline 16 & 1.38 & 0.30 & 0.43 & 30.26 & 35.41 & 0.37 & 0.30 \\
\hline 17 & 1.36 & 0.53 & 0.63 & 43.91 & 24.40 & 0.26 & 0.12 \\
\hline 18 & 0.75 & 0.31 & 0.36 & 32.02 & 33.46 & 0.28 & 0.47 \\
\hline 19 & 0.75 & 0.39 & 0.30 & 28.83 & 37.17 & 0.33 & 0.29 \\
\hline 20 & 0.77 & 0.29 & 0.25 & 35.48 & 30.20 & 0.22 & 0.23 \\
\hline 21 & 0.75 & 0.27 & 0.19 & 34.86 & 30.73 & 0.23 & 0.19 \\
\hline 22 & 1.77 & 0.77 & 0.80 & 32.81 & 32.66 & 0.15 & 0.17 \\
\hline
\end{tabular}


Table 3 Continued..

\begin{tabular}{|c|c|c|c|c|c|c|c|}
\hline \multirow{2}{*}{$\#$} & \multirow{2}{*}{$\begin{array}{l}\text { Normalization } \\
\text { factors }\end{array}$} & \multicolumn{2}{|c|}{ PGA [g] } & \multicolumn{2}{|c|}{ PGV $[\mathrm{cm} / \mathrm{s}]$} & \multicolumn{2}{|c|}{$\mathrm{Sa}_{1 \mathrm{~s}}[\mathrm{~g}]$} \\
\hline & & C1 & C2 & C1 & C2 & C1 & $\mathrm{C} 2$ \\
\hline 23 & 1.64 & 0.49 & 0.68 & 26.51 & 40.42 & 0.13 & 0.15 \\
\hline 24 & 1.54 & 0.77 & 0.91 & 32.24 & 33.23 & 0.22 & 0.28 \\
\hline 25 & 1.01 & 0.34 & 0.36 & 25.48 & 42.05 & 0.30 & 0.59 \\
\hline 26 & 0.92 & 0.27 & 0.28 & 37.49 & 28.58 & 0.66 & 0.34 \\
\hline
\end{tabular}

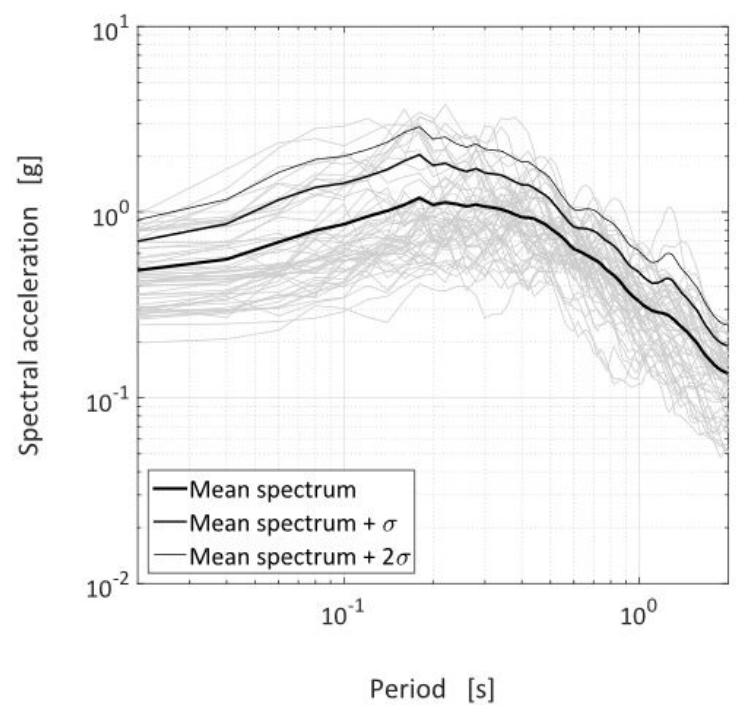

(a)

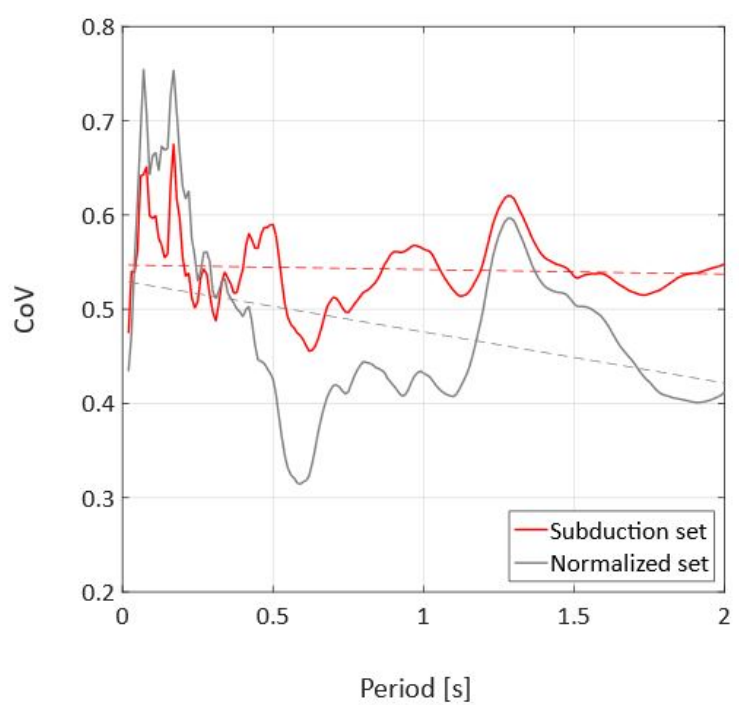

(b)

Figure 2 (a) Response spectra for the 26 pairs of normalized ground motions and average spectrum of the set plus one and two standard deviations; (b) CoV as a function of T for the subduction set before and after normalization.

According to the FEMA P-695 methodology, the scaling process has to be done based on the spectral acceleration $\mathrm{Sa}_{\mathrm{T} 1}$ corresponding to the fundamental period of the structure up to an intensity such that $50 \%$ of the records have caused collapse. To keep consistency with the methodology, the period for scaling $\mathrm{Sa}_{\mathrm{T} 1}$ is the code-defined fundamental period $T_{1}=C_{u} T_{a}$ and not the fundamental period obtained from eigenvalue analysis. This procedure is similar to that presented in the ASCE/SEl standard 7-16 (ASCE, 2016), with the exception that in the FEMA P-695 methodology the value of $\mathrm{Sa}_{\mathrm{T} 1}$ has to be adjusted to a given intensity for $\mathrm{T}_{1}$, and not for a range of periods.

\section{SPECTRAL SHAPE FACTORS}

Recent research has found that the calculation of the collapse capacity of structural systems through IDA analyses is influenced by the spectral shape of the ground motions, and several approaches have been proposed in order to measure both the spectral shape itself and its influence on the seismic response of structures. As noted by Eads et al. (2016), some relevant approaches to measure the spectral shape are (1) the epsilon parameter $\varepsilon$, defined as the number of standard deviations by which the spectral acceleration of a record is above or below the mean spectral acceleration calculated by a GMPE, (2) the parameter $\eta$, which is a linear combination of the epsilon parameter and of the number of standard deviations that the peak ground velocity of the record is above or below the one predicted by a GMPE, (3) the $\mathrm{Np}$ parameter, defined as the ratio of the geometric mean of the pseudo-acceleration spectral values over a period range from $T_{1}$ to $2 T_{1}$, to $\mathrm{Sa}\left(\mathrm{T}_{1}\right)$, and (4) the SaRatio parameter, which is the ratio of $\mathrm{Sa}_{\mathrm{T} 1}$ to the geometric mean of the pseudoacceleration spectral values over a period range. In order to be consistent with the FEMA P-695 methodology, in this paper the parameter epsilon $\varepsilon$ will be used as a measure of the spectral shape.

For seismic demands with a low probability of exceedance, such as the maximum considered earthquake (MCE), the spectral shape is considerably different from that observed in design spectra or in uniform hazard spectra (Baker, 2005; Baker and Cornell, 2006). These response spectra show peaked Sa values around a given period when their intensity (at such period) is close to the MCE level. This is because it is unlikely that a ground motion with a spectral acceleration much 
larger than the expected mean at one period also has large spectral accelerations at all other periods (FEMA, 2009). Intuitively, this peaked spectral shape is expected to result in positive $\varepsilon$ values. For instance, Baker (2005) showed that on the Coast of California the typical values of $\varepsilon$ range from 1.0 to 2.0 for ground motions at the MCE level (2\% in 50 years). These positive values of $\varepsilon$ are explained because the return period of the ground motion (i.e., 2475 years for a $2 \%$ exceedance probability in 50 years) is much larger than the return period of the earthquake that causes the ground motion (i.e., 150-500 years for typical events on the Coast of California).

On the other hand, it has been shown that collapse capacities calculated through dynamic analyses are higher for ground motions with a peaked spectral shape compared to records whose spectral shape does not peak. This is especially true when the peak is close to the fundamental period of the building and the seismic records are scaled based on SaT1, i.e., the first-mode spectral acceleration (Baker, 2005; Goulet et al., 2006; Haselton and Baker, 2006; Zareian, 2006). However, spectral accelerations for periods other than $\mathrm{T}_{1}$ are also important. When the structure responds in the nonlinear range, there is an elongation of the fundamental period which makes spectral accelerations beyond $\mathrm{T}_{1}$ to have a significant effect. Moreover, the influence of higher modes makes accelerations for periods shorter than $\mathrm{T}_{1}$ also important. Ground motions whose response spectrum has positive $\varepsilon$ values usually have lower spectral demands for periods away from $\mathrm{T}_{1}$.

It has been also shown that if ground motions with $\varepsilon\left(T_{1}\right)=0$ are used for collapse assessment when it is rather appropriate to use ground motions with $\varepsilon\left(T_{1}\right)=1.5-2.0$, collapse capacities can be underestimated by a factor of 1.3 to 1.8 times for relatively ductile structures (FEMA, 2009). The most appropriate approach to consider the spectral shape in collapse analyses is to select ground motions that have an appropriate value of epsilon at the fundamental period, depending on the site and hazard level of interest (Baker and Cornell, 2006). This approach is complex when evaluating different buildings with different fundamental periods, since a specific set of accelerograms should be considered for each of them. To deal with this problem, FEMA (2009) presented a simplified methodology to correct collapse capacities when a single set of accelerograms is used, which implicitly considers the effects associated with the spectral shape. Therefore, this section of the paper focuses on replicating such correction methodology for the set of ground motions proposed for subduction zones. The results can be replicated for any site under study after selecting an adequate target $\varepsilon 0$, as detailed in the following paragraphs.

Haselton and Deierlein (2007) investigated the relationship between the collapse capacity (expressed as the spectral acceleration of the fundamental period that causes collapse, $\mathrm{SC}_{\mathrm{T} 1}$ ) and the epsilon parameter $\varepsilon\left(\mathrm{T}_{1}\right)$, for which they analyzed a set of 65 modern reinforced concrete special moment frame buildings employing a set with 80 ground motions. It was found that $\mathrm{SC}_{\mathrm{T} 1}$ and $\varepsilon\left(\mathrm{T}_{1}\right)$ can be related through the following logarithmic function

$\ln \left(S_{C H 1}\right)=\beta_{0}+\beta_{1} \varepsilon\left(T_{1}\right)$

where $\beta_{0}$ indicates the average collapse capacity when $\varepsilon\left(T_{1}\right)=0$, and $\beta_{1}$ represents the sensitiveness of the collapse capacity to variations of $\varepsilon\left(T_{1}\right)$. Both parameters were obtained using linear regression procedures based on results from nonlinear dynamic analyses. It was found an average value of $\beta_{1}=0.29$ to be consistent for modern reinforced concrete special moment frame buildings with various heights. For buildings with a large inelastic deformation capacity (i.e., ductility), the fundamental period tends to increase considerably near collapse. Thus, spectral values higher than $\mathrm{T}_{1}$ become important and affect the structural response, the spectral shape has a larger impact, and the value of $\beta_{1}$ increases. To study this phenomenon, Haselton and Deierlein (2007) also investigated the response of 26 old reinforced concrete buildings which do not have modern ductility requirements, and found an average value of $\beta_{1}=0.18$, which is $35 \%$ lower than the average for buildings with special moment frames. In addition, 20 buildings with ordinary frames were also analyzed finding that $\beta_{1}=0.19$, confirming the existence of a relationship between the inelastic deformation capacity and the $\beta_{1}$ parameter.

FEMA (2009) developed a methodology to correct collapse capacities such that there is no need to calculate the value of $\varepsilon\left(T_{1}\right)$ for each building nor to obtain the value of $\beta_{1}$ by linear regression procedures. However, values of $\beta_{1}$ were necessary for several structural models with different inelastic deformation capacities. This was accomplished by analyzing the nonlinear dynamic results of a 118-buildings set. The set was comprised of: (1) 60 reinforced concrete special moment frame buildings (Haselton and Deierlein, 2007), (2) 16 reinforced concrete ordinary frame buildings (FEMA, 2009), (3) 26 non-ductile reinforced concrete buildings (Liel, 2008), and (4) 16 light-frame wooden buildings (FEMA, 2009). To consider the possible range of applications, the aforementioned set had buildings with different structural typologies, design criteria, and heights. For large inelastic deformation conditions, the elongation of the fundamental period $T_{1}$ can be related to the ductility $\mu_{T}$, which is defined as the ratio between the ultimate roof displacement (defined as the roof displacement associated with a $20 \%$ loss of base shear strength) obtained from static 
analyses, and the effective yield roof displacement. Therefore, $\mu_{\mathrm{T}}$ was used as a proxy to define a relationship between $\beta_{1}$ and the inelastic deformation capacity through the following equation (FEMA, 2009)

$$
\beta_{1}=0.14\left(\mu_{T}-1\right)^{0.12}
$$

where $\mu_{T} \leq 8.0$. Finally, an expression to calculate the spectral shape correction factors of the collapse capacity depending on the fundamental period of the structure was also developed by FEMA (2009)

$$
S S F=\operatorname{cxp}\left(\beta_{1}\left(\varepsilon_{0}-\varepsilon\left(T_{1}\right)\right)\right)
$$

where $\beta_{1}$ depends on the inelastic deformation capacity $\mu_{T}$ (Equation 4), $\varepsilon_{0}$ is the target $\varepsilon$ value which depends on both the site and the hazard level of interest, and $\varepsilon\left(\mathrm{T}_{1}\right)$ is the $\varepsilon$ value calculated for the fundamental period, based on the mean response spectrum of the set and an appropriate GMPE for the site under study. These last two parameters are discussed below.

Employing data from the United States Geological Survey (USGS), Harmsen (2001) and Harmsen et al. (2003) determined the target $\varepsilon_{0}$ values for the different seismic design categories in the ASCE/SEI 7-16 standard (ASCE, 2016) through probabilistic seismic hazard analyses and disaggregation. It was found that the values corresponding to $T=1 \mathrm{~s}$ at a hazard level of $0.5 \%$ of exceedance probability in 50 years were adequate. For seismic design categories $B$ and $C, \varepsilon_{0}$ was set to 1.0 , while for category $D, \varepsilon_{0}$ was set to 1.5 .

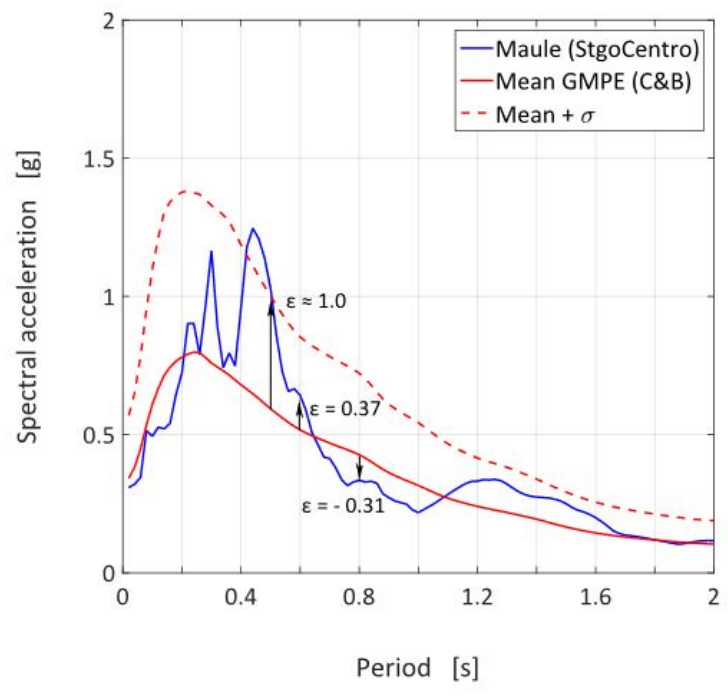

(a)

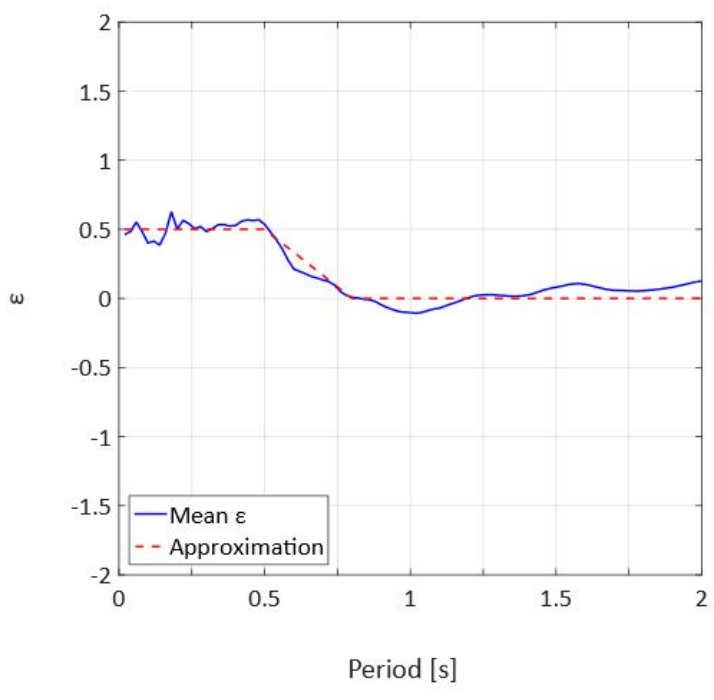

(b)

Figure 3 (a) Parameter $\varepsilon$ calculated for the Maule earthquake (Santiago Centro station) according to the GMPE proposed by Contreras and Boroschek (2012); (b) parameter $\varepsilon$ for periods up to $T=2 \mathrm{~s}$, calculated based on the average spectrum of the set and the GMPE proposed by Contreras and Boroschek (2012).

Parameter $\varepsilon$ depends both on the period and on the hazard level of the site under study, which is represented through a GMPE. In this research, the GMPE proposed by Contreras and Boroschek (2012) was employed, since it was developed based on a large set of subduction earthquakes and has proved to be accurate when predicting expected spectral intensities. As previously mentioned, the parameter $\varepsilon$ is defined as the number of standard deviations between a GMPE and the elastic response spectrum of a given ground motion. For instance, Figure 3(a) shows the response spectrum of the Maule earthquake recorded by the Santiago Centro station, the mean prediction of the GMPE, and the standard deviation. It can be seen that for $T=0.6 \mathrm{~s}, \varepsilon$ is equal to 0.37 , while for $T=0.8 \mathrm{~s}$ it changes to $\varepsilon=-0.31$. When $\mathrm{T}=0.5 \mathrm{~s}, \varepsilon$ is close to 1.0 .

When calculating correction factors to adjust collapse capacities through Equation 5 , it is necessary to have the $\varepsilon\left(T_{1}\right)$ parameter for different periods, calculated based on the average response spectrum of the ground motion set. For the set in this paper, the results are shown in Figure $3(b)$ for periods up to $T=2 \mathrm{~s}$. The average values of $\varepsilon$ are small and close to zero for periods greater than $0.8 \mathrm{~s}$. Hence, the proposed set is classified as ' $\varepsilon$-neutral' (FEMA, 2009). Furthermore, for 
short periods the values of $\varepsilon$ range from 0.4 to 0.6 , which is due to the high limit of PGA (>0.2 g) that was set in the selection of the records. For calculation purposes, it is useful to simplify the results shown in Figure 3(b) by a piecewise linear function given by

$$
\varepsilon(T)=\frac{4-5 T}{3}
$$

where $0 \leq \varepsilon(T) \leq 0.5$. Hence, using Equations 4, 5, and 6, and an adequate value of $\varepsilon_{0}$, it is possible to calculate collapse capacity correction factors (also called spectral shape factors SSF) for different buildings. Tables 4 and 5 present the correction factors for $\varepsilon_{0}=1.0$ and $\varepsilon_{0}=1.5$, respectively, which have been calculated for discrete values of fundamental period $\mathrm{T}_{1}$ and ductility capacity $\mu_{\mathrm{T}}$. Note that using the expressions aforementioned, it is possible to calculate the factors for any value that the variables take, which is recommended for the application of the FEMA P-695 methodology.

When $\varepsilon_{0}=1.0$, the spectral shape factors range from SSF $=1.00-1.37$, and SSF $=1.00-1.61$ for $\varepsilon_{0}=1.5$, being these results consistent with previous research (FEMA, 2009). Note that Equation 4 saturates for values of ductility capacity $\mu_{T}$ greater than 8 , thus if a structural archetype has a $\mu_{T}>8$, it must be assumed as $\mu_{T}=8$. In addition, to maintain consistency with the FEMA P-695 methodology, the ductility capacity $\mu_{\mathrm{T}}$ must be calculated with the expressions provided by the ASCE/SEI 41-17 standard (ASCE, 2017), which depends on both the period and the modal shape of the structure.

Table 4 Spectral shape factors for $\varepsilon_{0}=1.0$.

\begin{tabular}{cccccccccccc}
\hline Period & & \multicolumn{10}{c}{ Ductility $\boldsymbol{\mu}_{\mathrm{T}}$} \\
\hline$[\mathrm{s}]$ & $\mathbf{1 . 0}$ & $\mathbf{1 . 1}$ & $\mathbf{1 . 3}$ & $\mathbf{1 . 5}$ & $\mathbf{2 . 0}$ & $\mathbf{3 . 0}$ & $\mathbf{4 . 0}$ & $\mathbf{5 . 0}$ & $\mathbf{6 . 0}$ & $\mathbf{7 . 0}$ & $\mathbf{2 8 . 0}$ \\
$\leq 0.50$ & 1.00 & 1.03 & 1.04 & 1.05 & 1.07 & 1.10 & 1.12 & 1.13 & 1.15 & 1.16 & 1.17 \\
0.55 & 1.00 & 1.03 & 1.05 & 1.06 & 1.09 & 1.12 & 1.14 & 1.16 & 1.17 & 1.19 & 1.20 \\
0.60 & 1.00 & 1.04 & 1.06 & 1.07 & 1.10 & 1.13 & 1.16 & 1.18 & 1.20 & 1.22 & 1.24 \\
0.65 & 1.00 & 1.04 & 1.07 & 1.08 & 1.11 & 1.15 & 1.18 & 1.21 & 1.23 & 1.25 & 1.27 \\
0.70 & 1.00 & 1.05 & 1.07 & 1.09 & 1.12 & 1.17 & 1.20 & 1.23 & 1.26 & 1.28 & 1.30 \\
0.75 & 1.00 & 1.05 & 1.08 & 1.10 & 1.14 & 1.19 & 1.23 & 1.26 & 1.29 & 1.31 & 1.34 \\
$\geq 0.80$ & 1.00 & 1.05 & 1.09 & 1.11 & 1.15 & 1.21 & 1.25 & 1.28 & 1.32 & 1.35 & 1.37 \\
\hline
\end{tabular}

Table 5 Spectral shape factors for $\varepsilon_{0}=1.5$.

\begin{tabular}{cccccccccccc}
\hline Period & \multicolumn{10}{c}{ Ductility $\boldsymbol{\mu}_{\mathrm{T}}$} \\
\hline$[\mathrm{s}]$ & $\mathbf{1 . 0}$ & $\mathbf{1 . 1}$ & $\mathbf{1 . 3}$ & $\mathbf{1 . 5}$ & $\mathbf{2 . 0}$ & $\mathbf{3 . 0}$ & $\mathbf{4 . 0}$ & $\mathbf{5 . 0}$ & $\mathbf{6 . 0}$ & $\mathbf{7 . 0}$ & $\geq \mathbf{8 . 0}$ \\
$\leq 0.50$ & 1.00 & 1.05 & 1.09 & 1.11 & 1.15 & 1.21 & 1.25 & 1.28 & 1.32 & 1.35 & 1.37 \\
0.55 & 1.00 & 1.06 & 1.10 & 1.12 & 1.16 & 1.22 & 1.27 & 1.31 & 1.35 & 1.38 & 1.41 \\
0.60 & 1.00 & 1.06 & 1.10 & 1.13 & 1.18 & 1.24 & 1.30 & 1.34 & 1.38 & 1.41 & 1.45 \\
0.65 & 1.00 & 1.07 & 1.11 & 1.14 & 1.19 & 1.26 & 1.32 & 1.37 & 1.41 & 1.45 & 1.49 \\
0.70 & 1.00 & 1.07 & 1.12 & 1.15 & 1.21 & 1.28 & 1.34 & 1.40 & 1.44 & 1.49 & 1.53 \\
0.75 & 1.00 & 1.08 & 1.13 & 1.16 & 1.22 & 1.30 & 1.37 & 1.43 & 1.48 & 1.52 & 1.57 \\
$\geq 0.80$ & 1.00 & 1.08 & 1.14 & 1.17 & 1.23 & 1.32 & 1.40 & 1.46 & 1.51 & 1.56 & 1.61 \\
\hline
\end{tabular}

Figure 4(a) shows the spectral shape factors for the far-field set of the FEMA P-695 methodology and for the proposed subduction set, calculated for a fundamental period of $T_{1}=0.7 \mathrm{~s}$. As can be seen, both for $\varepsilon_{0}=1.0$ and $\varepsilon_{0}=1.5$, the spectral shape factors of the proposed subduction set are higher by, on average, $7.3 \%$. This is because, due to the higher amplitudes of the subduction records, the mean response spectrum of the set is "closer" to the spectral prediction from the GMPE, which results in lower epsilon values compared to those from the far-field set. As the values of $\varepsilon_{0}$ which define the seismic hazard are kept the same in both cases, it is easy to note that Equation 5 will result in higher SSFs to avoid over-conservative collapse capacities. This highlights that a proper quantification of the seismic hazard through the $\varepsilon_{0}$ parameter is crucial before applying the aforementioned procedure. Higher SSF values can play a fundamental role when evaluating the collapse capacity of buildings, or when validating a new set of seismic performance factors through the FEMA P-695 methodology since they modify directly the collapse margin ratios calculated from IDA analyses. These results also stand out the importance of a proper calculation of the SSF if new or different ground motion sets are used. 
The same trend of higher SSF is also observed for fundamental periods other than $0.7 \mathrm{~s}$. Additionally, it can also be noted from Figure 4(a) that the higher the ductility is, the higher the SSFs are, which is consistent with the results of Haselton and Deierlein (2007). For structural systems with larger inelastic deformation capacity, the effective period elongates considerably before the collapse, causing the spectral values at periods greater than $T_{1}$ to have a greater influence on collapse response. Hence, the spectral shape of the ground motions becomes more important.

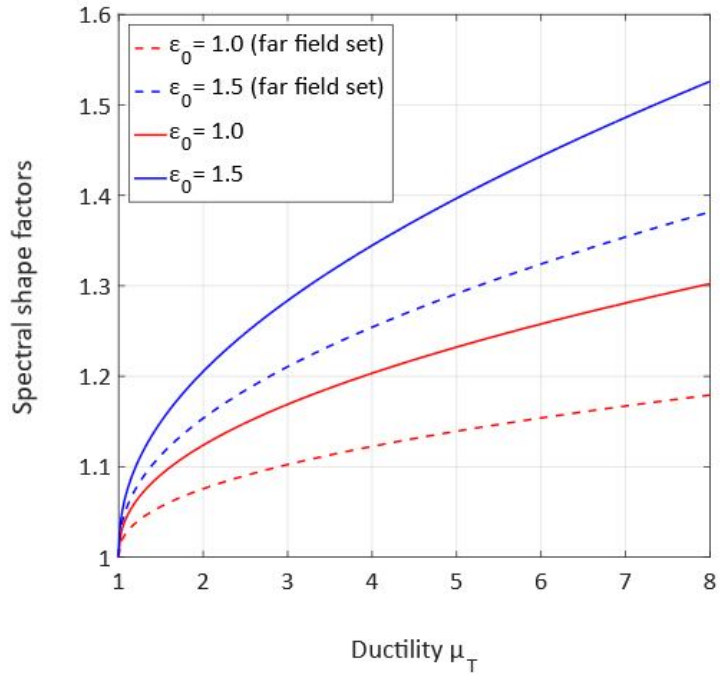

(a)

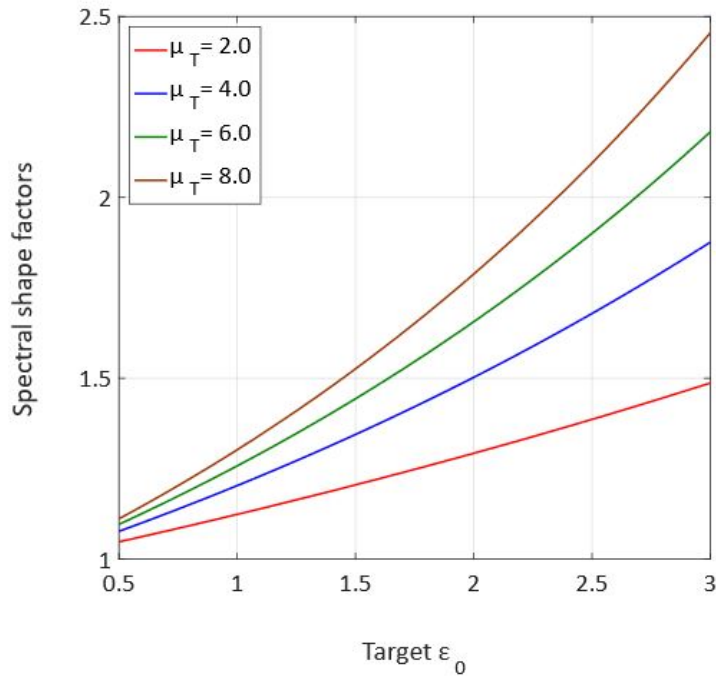

(b)

Figure 4 (a) Spectral shape factors for $T_{1}=0.7 \mathrm{~s}$, for both sets, (b) relationship between the target $\varepsilon_{0}$ parameter and the SSFs, for a fundamental period $T_{1}=0.7 \mathrm{~s}$ and different values of ductility.

Figure 4(b) shows the relationship between the target $\varepsilon_{0}$ parameter and the SSFs, for a fundamental period $\mathrm{T}_{1}=0.7 \mathrm{~s}$ and different values of ductility. It is interesting to note that the higher the ductility capacity, the higher the influence of the $\varepsilon_{0}$ on the calculation of the SSFs. For instance, whereas the ratio between the SSFs for $\varepsilon_{0}=3$ and $\varepsilon_{0}=0.5$ is 1.42 when $\mu_{\mathrm{T}}=2.0$, it is 2.21 when $\mu_{\mathrm{T}}=8.0$, an increment of $56 \%$ in the influence of $\varepsilon_{0}$. Hence, it highlights that an appropriate estimation of the $\varepsilon_{0}$ values is fundamental when adjusting collapse capacities based on the spectral shape parameter $\varepsilon$. For $T_{1}=1 \mathrm{~s}$, values of $\varepsilon_{0}=0.50$ to 1.25 are typical in zones other than the seismic regions of California. The values tend to be higher in most of California, since the earthquakes have shorter return periods, with typical values of $\varepsilon_{0}=1.25$ to 1.75 , and some values ranging upward to 3.0. On the other hand, $\varepsilon_{0}$ falls below 0.75 for the New Madrid Fault Zone, regions of the eastern coast, most of Florida, southern Texas, and areas in the north-west zone of the U.S. (FEMA, 2009; Harmsen, 2001; Harmsen et al., 2003).

\section{SEISMIC PERFORMANCE EVALUATION}

In this section, the impact of employing the proposed subduction set in nonlinear dynamic analyses is evaluated. Four modern 5-story light-frame wood buildings from Estrella et al. (2019) were included in the analyses, and the results were compared to those obtained by employing the FEMA P-695 far-field set. The buildings (named C, D, P, and Q respectively) were designed in accordance with the requirements of the Chilean seismic code NCh 433 (INN, 2009) and the SDPWS standard (American Wood Council, 2015) for a Seismic Zone 1 and a Soil Type B, as classified by the Chilean regulations. Figure 5 shows the floor plan of each building. 


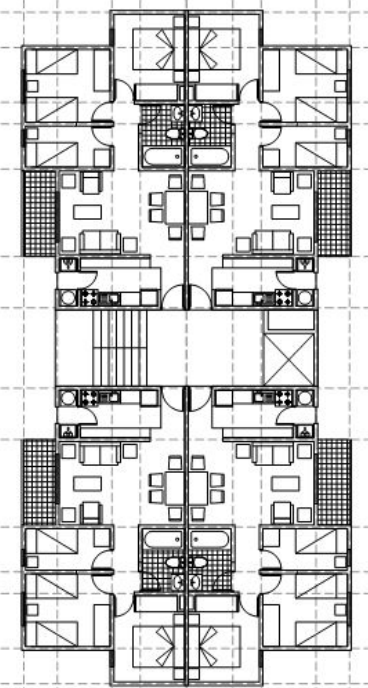

(a)

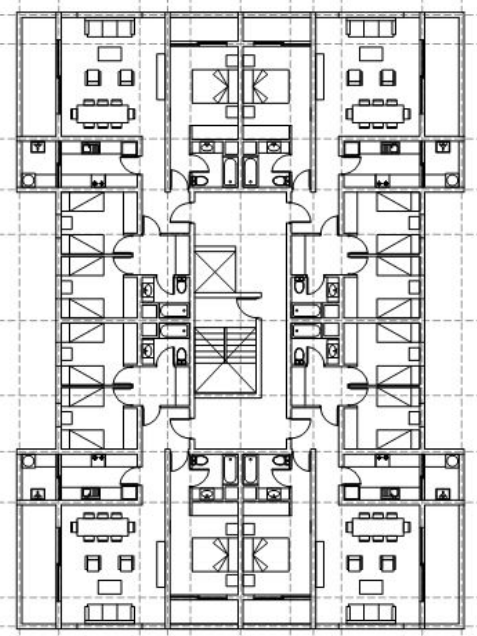

(b)

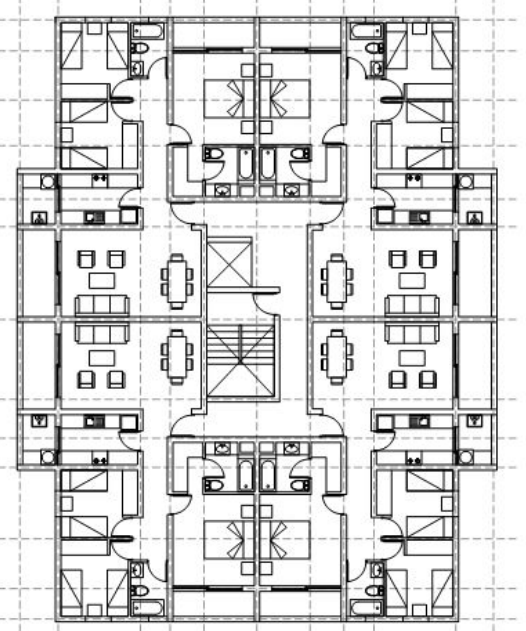

(c)

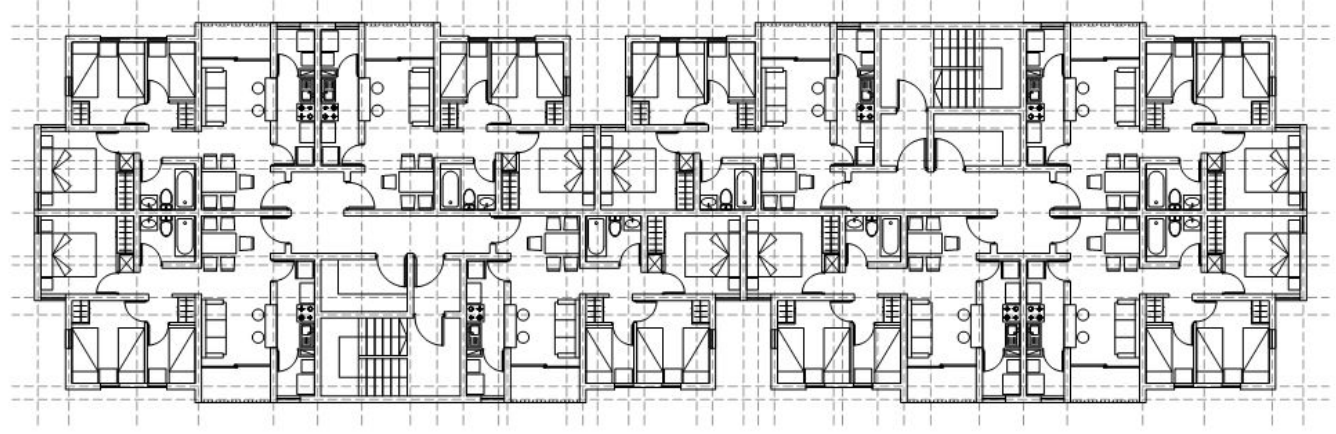

(d)

Figure 5 Architectural floor plan and wall distribution of: (a) building “ $C$ ”, (b) building “ $P$ ”, (c) building “ $Q$ ”, and (a) building “ $D$ ”.

A 3D nonlinear model was developed for each building. As proposed by Pei and van de Lindt (2009), light-frame walls were modeled using nonlinear spring elements which connect two consecutive floors. The hysteretic behavior of each light-frame wall was modeled using the Modified-Stewart (MSTEW) model proposed by Folz and Filiatrault (2001), which is able to properly capture phenomena associated to great damage states, such as force degradation, stiffness degradation, and pinching. Table 6 contains the MSTEW modeling parameters for wood frame walls of different configurations. The vertical flexibility of the buildings was modeled using a simplified bi-linear model which represents the combined stiffness of hold-downs, shear wall studs, continuous steel rods, and any special fastener devices. Figure 6 depicts the approach employed to model each wall.

To compute the collapse capacity of each building, bidirectional IDA analyses were conducted employing the software SAPWood V2.0 (Pei and van de Lindt, 2009) for both the subduction set and the far-field set, by scaling the ground motions until one-half of the records in the set caused collapse, which was defined as the occurrence of a $3 \%$ inter-story drift at any floor. The record pairs of both sets were applied twice to each model, once with the ground motion records oriented along the principal direction, and then again with the records rotated 90 degrees.

Table 6 MSTEW modeling parameters for wood frame walls.

\begin{tabular}{|c|c|c|c|c|c|c|c|c|c|c|c|}
\hline \multicolumn{2}{|c|}{ Wall properties } & \multicolumn{10}{|c|}{ MSTEW parameters } \\
\hline \multirow{2}{*}{ OSB } & Nail spacing & $K_{0}$ & & & & & $F_{0}$ & $F_{i}$ & $\delta_{u}$ & 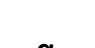 & 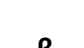 \\
\hline & {$[\mathrm{mm}]$} & {$[\mathrm{kN} / \mathrm{mm} / \mathrm{m}]$} & $r_{1}$ & $\sqrt{2}$ & $r_{3}$ & $r_{4}$ & $\overline{[\mathrm{kN} / \mathrm{m}]}$ & $\overline{[\mathrm{kN} / \mathrm{m}]}$ & {$[\mathrm{mm}]$} & $\alpha$ & $\boldsymbol{\beta}$ \\
\hline \multirow{3}{*}{ Single } & 50 & 2.374 & 0.072 & -0.046 & 1.000 & 0.017 & 10.275 & 2.048 & 45.450 & 0.532 & 1.139 \\
\hline & 100 & 1.393 & 0.079 & -0.101 & 1.047 & 0.015 & 9.600 & 1.603 & 57.300 & 0.531 & 1.146 \\
\hline & 150 & 1.080 & 0.079 & -0.090 & 1.075 & 0.014 & 7.104 & 1.202 & 55.820 & 0.522 & 1.150 \\
\hline
\end{tabular}


Table 6 Continued..

\begin{tabular}{|c|c|c|c|c|c|c|c|c|c|c|c|}
\hline \multicolumn{2}{|c|}{ Wall properties } & \multicolumn{10}{|c|}{ MSTEW parameters } \\
\hline \multirow{2}{*}{ OSB } & Nail spacing & $\mathrm{K}_{0}$ & \multirow{2}{*}{$r_{1}$} & \multirow{2}{*}{$\mathbf{r}_{2}$} & \multirow{2}{*}{$r_{3}$} & \multirow{2}{*}{$r_{4}$} & \multirow{2}{*}{$\frac{F_{0}}{[k N / m]}$} & \multirow{2}{*}{$\frac{F_{\mathbf{i}}}{[k N / m]}$} & \multirow{2}{*}{$\begin{array}{c}\delta_{\mathrm{u}} \\
{[\mathrm{mm}]}\end{array}$} & \multirow{2}{*}{$\alpha$} & \multirow{2}{*}{$\beta$} \\
\hline & [mm] & {$[\mathrm{kN} / \mathrm{mm} / \mathrm{m}]$} & & & & & & & & & \\
\hline \multirow{3}{*}{ Double } & 50 & 2.487 & 0.097 & -0.080 & 1.002 & 0.021 & 26.685 & 2.935 & 42.887 & 0.800 & 1.150 \\
\hline & 100 & 2.786 & 0.079 & -0.101 & 1.047 & 0.015 & 19.196 & 3.205 & 57.300 & 0.531 & 1.146 \\
\hline & 150 & 2.159 & 0.079 & -0.090 & 1.075 & 0.014 & 14.208 & 2.403 & 55.820 & 0.522 & 1.150 \\
\hline
\end{tabular}

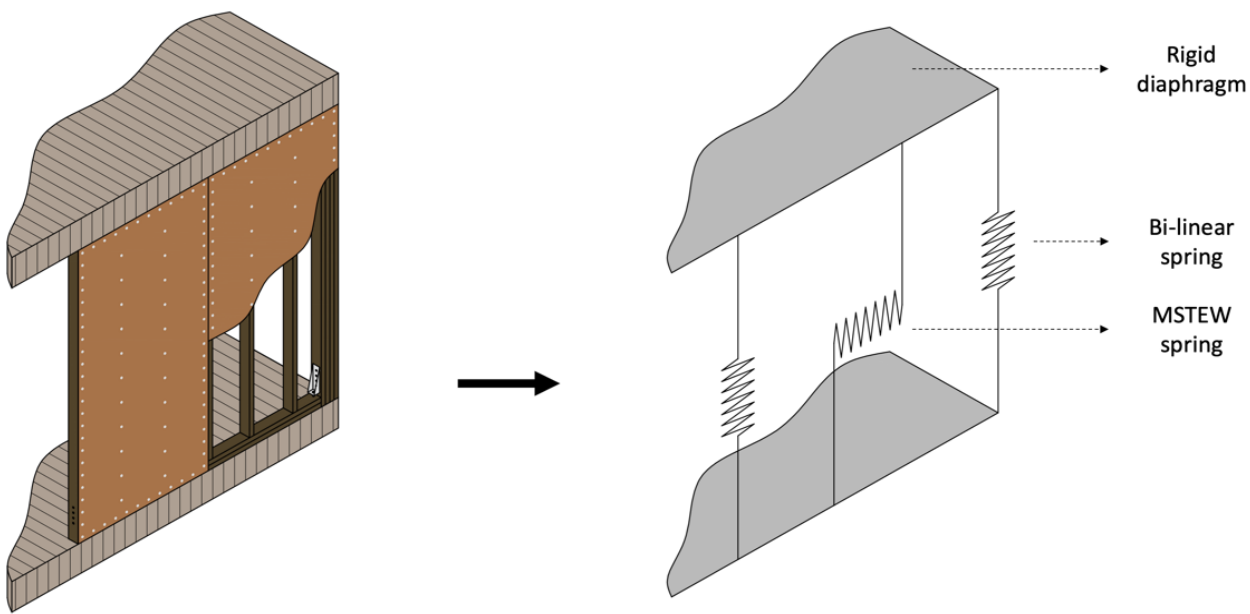

Figure 6 Modeling approach for wood frame walls.

Figure 7(a) shows the mean collapse capacities of each building computed for both the FEMA P-695 far-field set and for the subduction set. The results show a reduction in the collapse capacities of $14.7 \%, 12.0 \%, 10.1 \%$, and $12.7 \%$ for each building, respectively, when the subduction set is used in IDA analyses. The average reduction is $12.4 \%$. Lower collapse capacities are due to the longer duration of the set and to the greater energy that subduction earthquakes release. However, these results are different from those of previous research which found that the collapse capacity reduction can be as high as 40\% when employing large-duration records (Raghunandan et al., 2015). This difference is explained because the ground motion set proposed in this paper also includes short-duration records from shallow crustal earthquakes. This strategy was adopted to extend the applicability of the proposed set to zones with different hazard functions, site, and source conditions, as required by the FEMA P-695 methodology (2009).

Figure $7(\mathrm{a})$ also shows the variability when calculating the collapse capacities expressed as the coefficient of variation CoV. For the far-field set, the CoV ranges from 0.27 to 0.33 , and for the subduction set, it ranges from 0.30 to 0.38 . This uncertainty is due to variability in the response of the buildings to the different ground motion records in the sets and allows a proper evaluation of the structural seismic response when numerical models are employed. Previous research found that variability ranging from 0.35 to 0.45 is fairly consistent among various building types (Haselton, 2006; Ibarra and Krawinkler, 2005a, 2005b; Zareian, 2006). Hence, the variability provided by the proposed ground motion set is robust enough for a probabilistic evaluation of collapse capacities.

The adjusted collapse margin ratio (ACMR) is employed as a proxy to evaluate structural performance in the FEMA P-695 methodology. Firstly, the collapse margin ratio (CMR) is computed as the ratio between the mean collapse capacity obtained from IDA analyses and the spectral intensity related to the maximum considered earthquake provided by design codes. Subsequently, the CMR is adjusted to account for the effects of spectral shape by means of the spectral shape factors SSF, as described previously. Hence, ACMR = CMR x SSF. If three-dimensional models are used, a factor of 1.2 is applied to the ACMR to reduce the conservative bias which occurs when ground motion records are applied in pairs in three-dimensional nonlinear dynamic analyses (FEMA, 2009). 


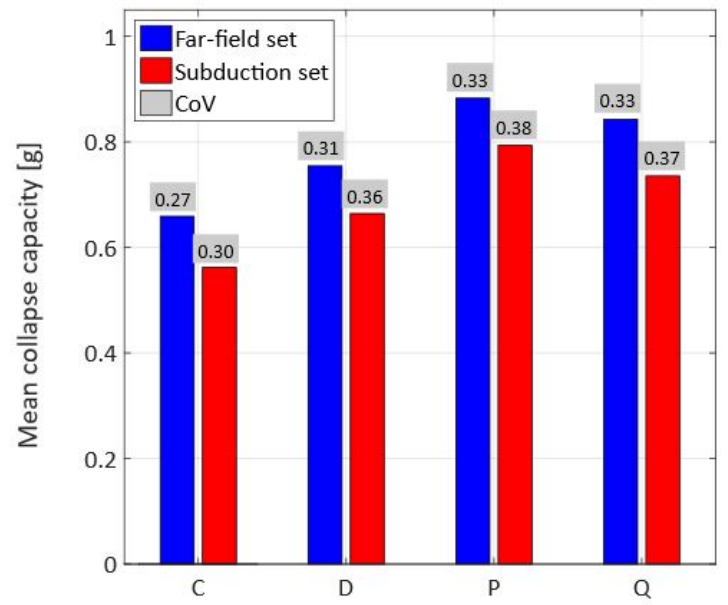

Building configuration

(a)

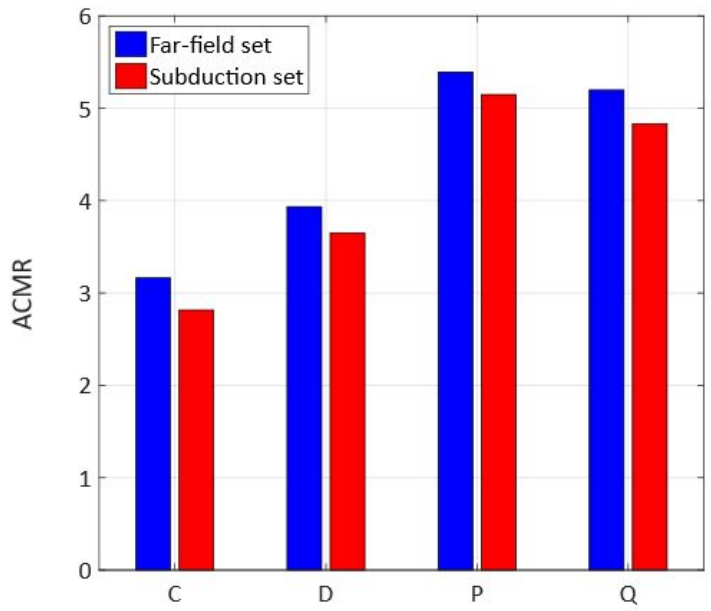

Building configuration

(b)

Figure 7 (a) Mean collapse capacities and CoV calculated for both the FEMA P-695 far-field set and the subduction set, (b) adjusted collapse margin ratios ACMR for both the FEMA P-695 far-field set and the subduction set.

Figure 7(b) shows the ACMRs calculated employing both ground motion sets. It can be noted that ACMRs decreases when the subduction set is employed, by $11.0 \%, 7.2 \%, 4.5 \%$, and $7.0 \%$, respectively. The average reduction is $7.4 \%$. Interestingly, the decrease percentages of the ACMRs are lower than those of the mean collapse capacities, a phenomenon which is mainly due to two reasons. First, the SSFs for the subduction set are, on average, higher than those for the far-field set. Hence, the CMRs are amplified by a higher factor. Second, light-frame buildings have a large inelastic deformation capacity, with ductilities which range from 4.0 to 5.0, and as observed in Figure 4(a), the larger the ductility, the higher the influence of the SSFs on the collapse capacities.

Intuitively, strong ground motions affect not only structural collapse capacities but also the behavior of nonstructural components in buildings, which is relevant for performance-based seismic engineering that takes into account economic losses and building functionality. In this context, horizontal floor accelerations are considered critical, since they impose forces that can lead to failures of non-structural components and their connections to the primary structural system. Figure 8(a) shows a comparison between the mean peak floor accelerations obtained from both the far-field set and the proposed subduction set. For this purpose, the ground motions of both sets were scaled to match a spectral acceleration of $\mathrm{Sa}_{\top 1}=0.25 \mathrm{~g}$, which is close to the MCE level for all buildings. It can be noted that there is an increase of $29.9 \%, 34.1 \%, 31.9 \%$, and $30.7 \%$ in the mean peak floor accelerations for each building when the subduction set is used. The average increase is $31.7 \%$. These higher floor acceleration values are due to the stronger ground motion of greater length that subduction earthquakes are known to have, and which transmits higher levels of kinetic energy to buildings.

The total dissipated hysteretic energy is known to be a good indicator of structural damage, since the deformation demands imposed on structural systems by earthquakes are cyclic in nature and the associated effects of cumulative damage can modify the seismic response of the structures (Kunnath and Chai, 2004) considerably. Hence, it is of relevant interest to analyze the impact of using the proposed subduction set to compute the cumulative energy dissipated by structural systems. Employing the records of both sets matched to a spectral acceleration of Sa $1=0.25 \mathrm{~g}$, the total mean hysteretic energy dissipated by all the light-frame walls of each building was calculated, and the results are shown in Figure $8(\mathrm{~b})$. When the subduction set is used to perform nonlinear dynamic analyses, the mean hysteretic energy increases by $38.0 \%, 18.1 \%, 1.1 \%$, and $5.8 \%$ for each building configuration, respectively. The mean increase is $15.7 \%$. It is interesting to note that the increment for the buildings $P$ and $Q$ is low compared to that of the buildings $C$ and $D$. This is because, as observed in Figures $7(\mathrm{a})$ and $7(\mathrm{~b})$, these buildings have higher collapse capacities; hence, ground motions scaled to a spectral acceleration of $\mathrm{Sa}_{\mathrm{T} 1}=0.25 \mathrm{~g}$ may not be strong enough to induce great damage to the structures regardless the ground motion set used in the analyses. As observed, higher amounts of dissipated hysteretic energy are due to the longer duration of the ground motions as well as to greater amplitude accelerations in the records. A proper quantification of the hysteretic energy is of relevant interest for performance-based seismic design approaches, since damage evaluation based on peak responses has found not to be an adequate measure of the potential damage of a ground motion, and therefore not a suitable indicator of structural performance because the strength, deformation, and energy-dissipation capacity of the building depend on the number of inelastic load cycles (Malhotra, 2002). 


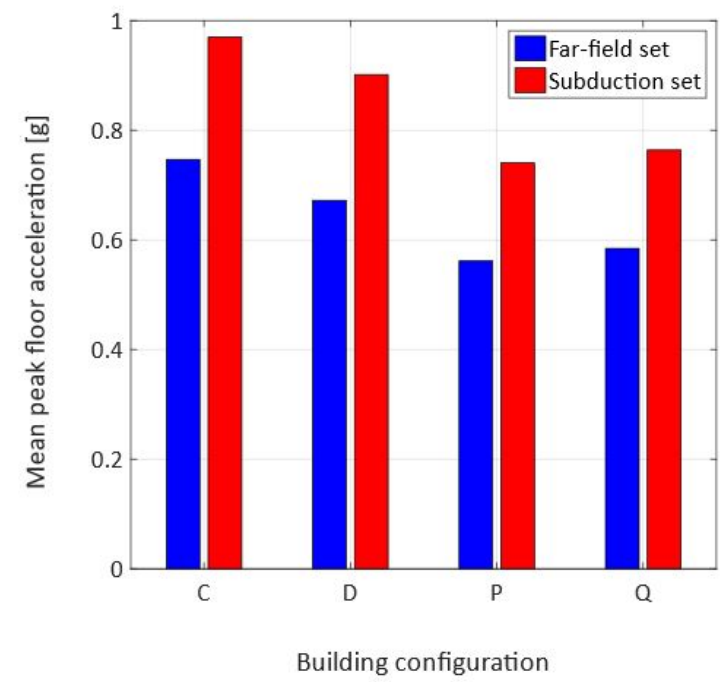

(a)

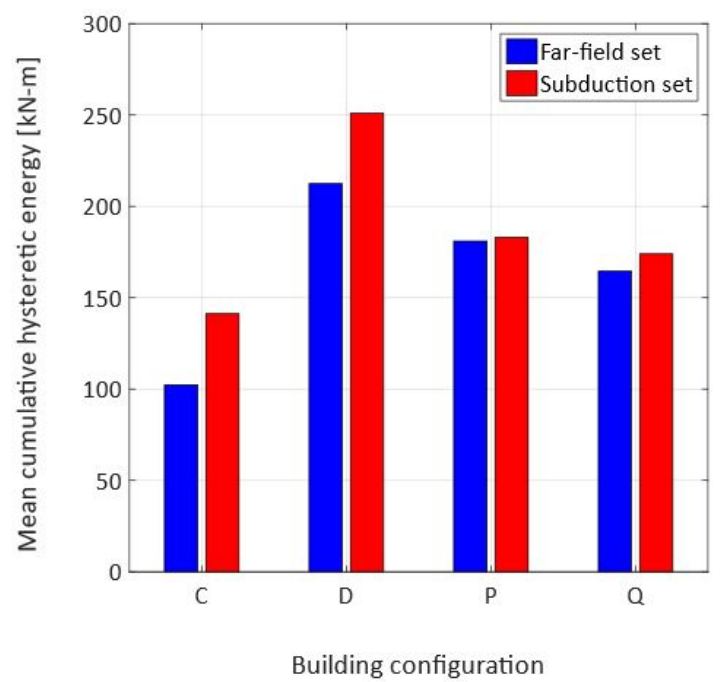

(b)

Figure 8 (a) Mean peak floor accelerations for both the FEMA P-695 far-field set and the subduction set; (b) mean cumulative hysteretic energy for both the FEMA P-695 far-field set and the subduction set.

\section{ROBUSTNESS ANALYSIS}

This section is aimed at evaluating the robustness of the proposed subduction set and of the criteria applied to select the ground motions, in order to demonstrate that collapse capacity predictions are not highly sensitive to small variations in the selection criteria and to validate the suitability of the number of records included. This latter is of relevant interest when performing IDA analyses, since although ground motion sets are required to have a sufficiently large number of records to compute mean collapse capacities properly, it is also essential to find a balance between the number of records necessary to suitably consider the variability of the seismic demand and the computational overheads related to performing nonlinear incremental dynamic analyses.

The robustness of the proposed subduction set was validated by comparing the previously computed collapse capacities to those obtained with a different set of ground motions proposed by Guerrero (2018). Such set consists of 209 pairs of ground motions recorded from interplate and intraplate earthquakes that occurred between 1985 and 2016 of magnitudes from 5.0 to 8.8. The PGA values in the set range from $0.04 \mathrm{~g}$ to $0.93 \mathrm{~g}$, with an average PGA of $0.23 \mathrm{~g}$. PGVs range from $0.59 \mathrm{~cm} / \mathrm{s}$ to $69.28 \mathrm{~cm} / \mathrm{s}$, with an average of $14.5 \mathrm{~cm} / \mathrm{s}$. The mean significant duration $\mathrm{Ds}_{5-75}$ of the set is $14.51 \mathrm{~s}$. Figure 9 shows the mean collapse capacities for the four previously discussed light-frame buildings computed through IDA analyses for both the proposed subduction set and the Guerrero (2018) set.

The results show that the collapse capacities calculated with the larger ground motion set are slightly higher than those calculated using the proposed subduction set, with increases of $8.7 \%, 4.6 \%, 1.5 \%$, and $4.2 \%$ for each building, respectively. The mean increase is $4.8 \%$. The variability, measured as the CoV, also increases and ranges from 0.41 to 0.46 , which is due to the wider interval of record intensities in the set proposed by Guerrero (2018). Interestingly, the data from Figure 9 indicates that the proposed subduction set is robust enough (in terms of the number of records and intensity levels) to provide the same reliability that can be obtained when employing a much larger ground motion set. Similarly, the results also show that collapse capacities are not highly sensitive to the PGA and PGV limits established when selecting ground motions, since records are scaled upwards in IDA analyses. This latter is of relevant interest, since there are few earthquake records with high PGA and PGV values available in the current literature for engineering purposes. Hence, including records with low-intensity levels can also be a suitable strategy when performing IDA analyses. 


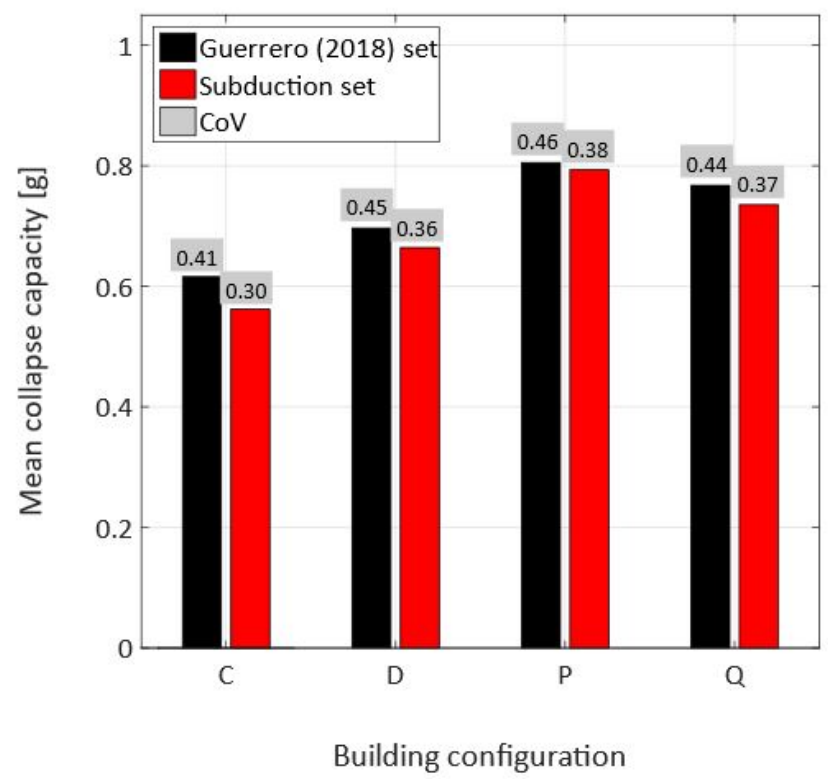

Figure 9 Mean collapse capacities and CoV calculated for both the set developed by Guerrero (2018) and the proposed subduction set.

\section{CONCLUSIONS}

This paper proposes a set of 26 pairs of ground motions aimed at extending the scope of the FEMA P-695 methodology to zones prone to subduction earthquakes, since the current FEMA P-695 record sets are representative only of shallow crustal earthquakes. The criteria to select the ground motions were designed to be consistent with those proposed in the FEMA methodology, to provide an objective selection of the records, and to embrace different ground motion hazard functions, sites, and source conditions. The proposed set contains 18 ground motions from subduction earthquakes and 8 from shallow crustal ones, recorded between 1987 and 2016 with magnitudes from 6.5 to 9.0. The average significant duration of the set is $14.56 \mathrm{~s}$, more than twice that of the FEMA P-695 far-field set. To properly consider the effects of the spectral shape when computing collapse capacities, the spectral shape correction factors were calculated using the ground motion prediction equation proposed by Contreras and Boroschek (2012) for different fundamental periods and ductility capacities, which were found to be $7.3 \%$ higher (on average) than those of the FEMA P-695 far-field set.

Nonlinear incremental dynamic analyses of four five-story light-frame buildings revealed that, when the proposed ground motion set is used, collapse capacities and adjusted collapse margin ratios decreased by $12.4 \%$ and $7.4 \%$, and peak floor accelerations and dissipated hysteretic energies increased by $31.7 \%$ and $15.7 \%$, respectively. Additionally, the robustness of the proposed set was verified by comparing the collapse capacity results with those obtained using a set with 209 pairs of ground motions collected employing different selection criteria. The results showed that the proposed subduction set is robust enough in terms of the number of records and intensity levels to provide the same reliability that can be obtained when employing a much larger ground motion set. Although these results were computed only from light-frame buildings, they highlight that subduction ground motions can induce greater damage than shallow crustal ones to structures with high deformation capacities and rapid rates of cyclic deterioration. Besides, as previous research has shown, similar trends can be expected for other structural systems (FEMA, 2009).

Additionally, the following general conclusions can also be drawn from the results of this paper:

- Normalization procedures for ground motion sets based on the median peak ground velocity are not very effective in reducing the variability of the set, especially for short periods.

- Both ductility capacity $\mathrm{u}_{\mathrm{T}}$ and target epsilon $\varepsilon_{0}$ have a significant impact when computing spectral shape factors. The higher the ductility or the target epsilon, the higher the spectral shape factors.

- Collapse capacities are not highly sensitive to the PGA and PGV limits established when selecting ground motions. Since there are few earthquake records with high PGA and PGV values available for engineering purposes, including records with low-intensity levels is also a suitable strategy when performing IDA analyses.

The subduction set proposed in this paper was developed with the purpose of being a tool for engineers and researchers when applying the guidelines of the FEMA P-695 methodology to quantify seismic performance factors of 
structural systems. Although the set pretends to be suitable for a wide range of seismic threats and engineering applications, special care must be taken when evaluating sites with special conditions (such as those near active faults), structures with very long periods, or buildings with significant irregularities.

\section{SUPPLEMENTAL DATA}

A database with the ground motion set proposed in this paper is available in this link_or through the corresponding author.

\section{ACKNOWLEDGMENTS}

Special thanks are due to the seismological agencies that contributed with ground motions for the development of this project. This research has been supported by the research grant project CONICYT FONDECYT 11.170.863. This research has also been funded by CONICYT-PFCHA/Doctorado Nacional/2019-21191267, VRI-UC, and UTS Graduate Research School.

Author's contributions: Conceptualization, X Estrella, P Guindos and JL Almazán; Methodology, X Estrella, P Guindos and JL Almazán; Writing - original draft, X Estrella; Writing - review \& editing, P Guindos and JL Almazán; Funding acquisition, P Guindos.

Editor: Marcílio Alves.

\section{REFERENCES}

AlHamaydeh, M., Abdullah, S., Hamid, A., Mustapha, A. (2011). Seismic design factors for RC special moment resisting frames in Dubai, UAE. Earthquake Engineering and Engineering Vibration, 10: 495-506.

American Wood Council. (2015). Special design provisions for wind and seismic. ANSI/AWC SDPWS-2015, Leesburg, VA.

ASCE. (2016). Minimum design loads and associated criteria for buildings and other structures. ASCE Standard ASCE/SEI 7-16, American Society of Civil Engineers, Reston, Virginia.

ASCE. (2017). Seismic evaluation and retrofit of existing buildings. ASCE Standard ASCE/SEI 41-17, American Society of Civil Engineers, Reston, Virginia.

Baker, J. (2005). Vector-valued ground motion intensity measures for probabilistic seismic demand analysis. Ph.D. Dissertation, Department of Civil and Environmental Engineering, Stanford University, Stanford, CA.

Baker, J. (2010). Conditional mean spectrum: tool for ground-motion selection. Journal of Structural Engineering, 137(3): 322331.

Baker, J., Cornell, C. (2005). Vector-valued ground motion intensity measures for probabilistic seismic demand analysis. Report \#150, John A. Blume Earthquake Engineering Center, Stanford, CA.

Baker, J., Cornell, C. (2006). Spectral shape, epsilon and record selection. Earthquake Engineering and Structural Dynamics, 35(9): 1077-1095.

Bezabeh, M., Tesfamariam, S., Popovski, M. (2016). Seismic base shear modification factors for timber- steel hybrid structure: steel moment resisting frames with CLT infill walls. In Proceedings of the 2016 World Conference on Timber Engineering. Vienna, Austria.

Bommer, J., Acevedo, A. (2004). The use of real earthquake accelerograms as input to dynamic analysis. Journal of Earthquake Engineering, 8(1): 43-91.

Bommer, J., Acevedo, A., Douglas, J. (2003). The selection and scaling of real earthquake accelerograms for use in seismic design and assessment. In Proceedings of the international conference on seismic bridge design and retrofit. La Jolla, California: American Concrete Institute. 
Campbell, K., Borzorgnia, Y. (2003). Updated near-source ground-motion (attenuation) relations for the horizontal and vertical components of peak ground acceleration and acceleration response spectra. Bulletin of the Seismological Society of America, 93(1): 314-331.

Ccanchi, E., Taboada, A. (2018). Evaluation of the seismic performance of a dwelling of confined masonry walls. In Proceedings of the 11th International Conference on Structural Analysis of Historical Constructions. Cusco, Peru.

Chandramohan, R. (2016). Duration of earthquake ground motion: influence on structural collapse risk and integration in design and assessment practice. Ph.D. Dissertation, Department of Civil and Environmental Engineering, Stanford University, Stanford, CA.

Chandramohan, R., Baker, J., Deierlein, G. (2016). Quantifying the influence of ground motion duration on structural collapse capacity using spectrally equivalent records. Earthquake Spectra, 32(2): 927-950.

Contreras, V., Boroschek, R. (2012). Strong ground motion attenuation relations for Chilean subduction zone interface earthquakes. In 15th World Conference on Earthquake Engineering. Lisbon, Portugal.

Cornell, C. (2005). On earthquake record selection for nonlinear dynamic analysis. In Proceedings of the Luis Esteva symposium. Mexico City, Mexico.

Eads, L., Miranda, E., Lignos, D. (2016). Spectral shape metrics and structural collapse potential. Earthquake Engineering and Structural Dynamics, 45: 1643-1659.

Estrella, X., Almazán, J., Guindos, P., Santa María, H. (2019). Factores de diseño sísmico para edificaciones marco-plataforma en Chile. In XII Congreso Chileno de Sismología e Ingeniería Sísmica. Valdivia, Chile.

FEMA. (2009). Quantification of building seismic performance factors. Federal Emergency Management Agency, Washington, D.C.

Folz, B., Filiatrault, A. (2001). Cyclic analysis of wood shear walls. Journal of Structural Engineering, 127(4): 433-441.

Foschaar, J., Baker, J., Deierlein, G. (2012). Preliminary assessment of ground motion duration effects on structural collapse. In 15th World Conference on Earthquake Engineering. Lisbon, Portugal.

Goulet, C., Haselton, C., Mitrani-Reiser, J., Beck, J., Deierlein, G., Porter, K., Stewart, J. (2006). Evaluation of the seismic performance of a code-conforming reinforced-concrete frame building - from seismic hazard to collapse safety and economic losses. Earthquake Engineering and Structural Dynamics, 36(13): 1973-1997.

Guerrero, A. (2018). Propuesta de formas espectrales para las normas chilenas de diseño sísmico. Master Dissertation, Department of Structural and Geotechnical Engineering, Pontificia Universidad Católica de Chile, Santiago, Chile.

Harmsen, S. (2001). Mean and modal $\varepsilon$ in the deaggregation of probabilistic ground motion. Bulletin of the Seismological Society of America, 91(6): 1537-1552.

Harmsen, S., Frankel, A., Petersen, M. (2003). Deaggregation of U.S. seismic hazard sources: The 2002 Update. U.S. Geological Survey Open-File Report 03-440, Sunrise Valley Drive Reston, VA.

Haselton, C. (2006). Assessing seismic collapse safety of modern reinforced concrete moment-frame buildings. Ph.D. Dissertation, Department of Civil and Environmental Engineering, Stanford University, Stanford, CA.

Haselton, C., Baker, J. (2006). Ground motion intensity measures for collapse capacity prediction: choice of optimal spectral period and effect of spectral shape. In Proceedings 8th National Conference on Earthquake Engineering. San Francisco, CA.

Haselton, C., Deierlein, G. (2007). Assessing seismic collapse safety of modern reinforced concrete frame buildings. Technical Report No. 156, John A. Blume Earthquake Engineering Center, Stanford University, Stanford, CA.

Ibarra, L., Krawinkler, H. (2005a). Effect of uncertainty in system deterioration parameters on the variance of collapse capacity. In 9th International Conference on Structural Safety and Reliability. Rome, Italy.

Ibarra, L., Krawinkler, H. (2005b). Global collapse of frame structures under seismic excitations. PEER Report 2005/06, and John A. Blume Earthquake Engineering Center Technical Report No.152, Department of Civil Engineering, Stanford University, Stanford, CA.

lervolino, I., Maddaloni, G., Cosenza, E. (2008). Eurocode 8 compliant real record sets for seismic analysis of structures. Journal of Earthquake Engineering, 12(1): 54-90. 
INN. (2009). Diseño sísmico de edificios. NCh 433.Of1996Mod2012, Instituto Nacional de Normalización, Santiago, Chile.

Katsanos, E., Sextos, A., Manolis, G. (2010). Selection of earthquake ground motion records: a state-of-the-art review from a structural engineering perspective. Soil Dynamics and Earthquake Engineering, 30: 157-169.

Kunnath, S., Chai, Y. (2004). Cumulative damage-based inelastic cyclic demand spectrum. Earthquake Engineering and Structural Dynamics, 33(4): 499-520.

Liel, B. (2008). Assessing the collapse risk of California's existing reinforced concrete frame structure: metrics for seismic safety decisions. Ph.D. Dissertation, Department of Civil and Environmental Engineering, Stanford University, Stanford, CA.

Malhotra, P. (2002). Cyclic-demand spectrum. Earthquake Engineering and Structural Dynamics, 31(7): 1441-1457.

PEER. (2002). PEER NGA database. Pacific Earthquake Engineering Research Center, University of California, Berkeley, CA.

Pei, S., van de Lindt, J. (2009). Coupled shear-bending formulation for seismic analysis of stacked wood shear wall systems. Earthquake Engineering and Structural Dynamics, 38: 1631-1647.

Raghunandan, M., Liel, A. (2013). Effect of ground motion duration on earthquake-induced structural collapse. Structural Safety, 41: 119-133.

Raghunandan, M., Liel, A., Luco, N. (2015). Collapse risk of buildings in the Pacific Northwest Region due to subduction earthquakes. Earthquake Spectra, 31(4): 2087-2115.

Shome, N., Cornell, C. (1999). Probabilistic seismic demand analysis of nonlinear structures. RMS Program, Stanford, CA.

Vamvatsikos, D., Cornell, C. (2002). Incremental dynamic analysis. Earthquake Engineering and Structural Dynamics, 31(3): 491-514.

Vielma, J., Cando, M. (2017). Evaluación del factor de comportamiento de la Norma Ecuatoriana de la Construcción para estructuras metálicas porticadas. Revista Internacional de Métodos Numéricos Para Cálculo y Diseño En Ingeniería, 33(3): 271279.

Zareian, F. (2006). Simplified performance-based earthquake engineering. Ph.D. Dissertation, Department of Civil and Environmental Engineering, Stanford University, Stanford, CA. 